\title{
DIREITO, DESENVOLVIMENTO SUSTENTÁVEL E A EXPLORAÇÃO ENERGÉTICA DO GÁS DE XISTO NO BRASIL
}

Law, sustainable development and the energy exploitation of shale gas in Brazil

\author{
Ana Carla Pinheiro Freitas ${ }^{1}$ \\ Liane Maria Santiago Cavalcante Araujo² \\ Thiago Flores dos Santos ${ }^{3}$
}

RESUMO

A produção energética através da exploração econômica do gás de xisto tem sido objeto de intenso debate no Brasil, especialmente, no que diz respeito aos impactos sociais e ambientais que esse tipo de atividade pode ocasionar. Por meio deste trabalho analisou-se as metodologias e impactos resultantes da exploração do gás de xisto, com base nas experiências de outros países, bem como, abordou-se sob a ótica do desenvolvimento sustentável os instrumentos normativos e rodadas de licitações que vem sendo implementadas no país que com o objetivo de viabilizar-se o exercício dessa atividade econômica. A metodologia utilizada foi a pesquisa bibliográfica e documental e foram adotados os métodos analítico e descritivo para a abordagem da problemática proposta. Como resultado ficou demonstrado que as iniciativas do Poder Público, por meio da Agência Nacional do Petróleo - ANP, para a exploração do gás de xisto no Brasil não estão sendo realizadas com plena observância dos postulados e princípios previstos no art. 225 da Constituição. O presente estudo contribui para uma reflexão crítica acerca da exploração energética do gás de xisto no Brasil, levando-se em consideração os possíveis impactos que podem advir desse processo e o dever constitucional de manutenção do meio ambiente ecologicamente equilibrado.

Palavras-chave: Gás de xisto. Economia. Meio Ambiente. Licitações Públicas. Desenvolvimento sustentável.

\footnotetext{
1 Doutora em Direito pela Pontifícia Universidade Católica de São Paulo. Professora Titular dos cursos de mestrado e doutorado da Universidade de Fortaleza - UNIFOr, Ceará. ORCID iD: http://orcid.org/0000-0002-4382-7599. Institui ção: Universidade de Fortaleza - UNIFOR, Ceará. Brasil. Email: cpinheirofreitas@yahoo.com.br

2 Doutoranda em Direito Constitucional pela Universidade de Fortaleza. Mestre em Direito Constitucional pela Universidade de Fortaleza. Especialista em Direito Processual: Grandes Transformações pela UNISUL. Bolsista FUNCAP-CAPES/BRASIL. ORCID iD: http://orcid.org/0000-0003-3428-522X. Instituição: Universidade de Fortaleza - UNIFOR, Ceará. Brasil. E-mail: lianemariaadv@gmail.com

${ }^{3}$ Doutorando em Direito Constitucional na Universidade de Fortaleza - UNIFOR, Ceará. Mestre em Direito Ambiental. Professor universitário e gerente jurídico na Eletrobrás Distribuição Amazônia. Instituição: Universidade de Fortaleza - UNIFOR, Ceará. Brasil. E-mail: thiagoflores.adv@gmail.com
} 


\section{ABSTRACT}

Energy production through the economic exploration of shale gas has been the subject of intense debate in Brazil, especially with regard to the social and environmental impacts that this type of activity can cause. Through the present work, the methodologies and impacts resulting from the exploitation of shale gas were analyzed, based on the experiences of other countries, as well as, approached in the perspective of sustainable development the normative instruments and rounds of Bids that have been implemented in the country that with the objective of making the exercise of this economic activity viable. The methodology used was the bibliographical and documentary research and the analytical and descriptive methods were adopted for the approach of the problematic proposal. As a result, the need for technological advances in the face of traditional forms of exploration of shale gas and the environmental impacts that can be brought about by this activity has been demonstrated. It was also found that the public power initiatives, through the National Petroleum Agency - ANP, for the exploration of shale gas in Brazil are not being carried out with full observance of the postulates and principles foreseen in art. 225 of the Constitution. This study contributes to a critical reflection on the energy exploitation of shale gas in Brazil, taking into account the possible impacts that may arise from this process and the constitutional duty of environmental maintenance ecologically balanced.

Keywords: Shale Gas. Economy. Environment. Public bids. Sustainable development.

\section{INTRODUÇÃO}

A Constituição de 1988 foi a primeira a fazer menção ao meio ambiente, protegendo-o da degradação que tem sofrido nos últimos anos, de forma alarmante. A constitucionalização dessa proteção surgiu na condição de instrumental sólido para atuação em defesa desse direito fundamental tão relevante, como forma de garantir um ambiente adequado e propício à vida e determinar ao poder público o dever de reprimir e controlar as ameaças ao funcionamento sistêmico e sustentável do meio ambiente.

O meio ambiente classifica-se em ambiente físico, cultural, natural e do trabalho, e possui natureza jurídica de bem público de uso comum do povo. Logo, todas essas vertentes encontram-se abrangidas pelo conceito constitucional de "meio ambiente ecologicamente equilibrado". É nessa perspectiva que a industrialização do xisto merece especial atenção do Estado e da sociedade como 
um todo, uma vez que há fortes indícios de que a exploração dessa matriz energética encontra-se prejudicada por sua inviabilidade econômica e ambiental.

Assim, o primeiro tópico do estudo aprofunda a análise acerca da (in)viabilidade econômica e ambiental da exploração do xisto no cenário nacional e internacional. Para tanto, são avaliadas as condições e consequências da exploração do xisto em solo brasileiro pela Petrobras, no município de São Mateus do Sul, no Paraná, como fonte de energia. Em um segundo momento, propõe-se uma incursão nas rodadas de licitações para a exploração do gás de xisto no Brasil, com destaque para os entraves jurisdicionais que vêm sendo enfrentados pelo Poder Público, por questões de risco ambiental, para colocar em prática tais concessões.

Parte-se, então, para a análise das propostas governamentais brasileiras para a exploração do gás de xisto. Por fim, é realizado um paralelo entre a exploração do gás de xisto, como alternativa energética, e o desenvolvimento sustentável no brasil, partindo-se dos aspectos jurídicos do gerenciamento de riscos na exploração de gás de xisto. A esta altura, propõe-se a seguinte reflexão: o desenvolvimento sustentável constitui requisito à exploração energética do gás de xisto no Brasil?

Trata-se de pesquisa qualitativa, descritiva, documental e bibliográfica, voltada para a apreciação de leis, documentos e jurisprudências, com o propósito de aliar o estudo da ciência do direito e da realidade dos fatos, de forma a apresentar resultados passíveis de serem apropriados pela sociedade, de forma a colaborar para uma maior qualidade de vida para as atuais e futuras gerações.

\section{XISTO E A (IN)VIABILIDADE ECONÔMICA E AMBIENTAL DE SUA EXPLORAÇÃO}

Ao passo em que o debate acerca da substituição do petróleo por fontes não convencionais não renováveis (como o xisto, as areias oleosas) ou renováveis (como a energia solar, eólica e biomassa) ganha força no cenário politico e econômico nacional e internacional, multiplicam-se os estudos de viabilidade econômica e ambiental da exploração do xisto, por representar a possibilidade de freio da alta incontrolável do preço do barril de petróleo. Como um novo modelo energético, argumenta-se que o xisto representa, nesta perspectiva, a transição de um sistema mundial de energia para um novo modelo, mais diversificado, capaz de combater a possibilidade de exaustão dos recursos, amenizar os conflitos políticos e, também promover e preservar as questões ambientais correlatas (DOS SANTOS; MATAI, 2010).

A expressão "xisto" é incorretamente aplicada para identificar rochas sedimentares constituídas de finas camadas, cuja denominação correta é folhelho oleígeno. Em sua matriz mineral, há um material orgânico denominado querogênio ou betume, que se decompõe, com a influência da temperatura, produzindo assim óleo e gás. Os principais depósitos de gás de xisto situam-se, de 
uma maneira geral, em profundidades menores que 1000 metros, distribuídos em camadas de espessuras variadas, com um teor de querogênio também variável. Encontram-se espalhados nos cinco continentes, destacando-se, pela quantidade de recursos, os países do Canadá, Estônia, China, Rússia, Austrália, Brasil, Estados Unidos, Jordânia, Zaire, Marrocos e Itália (DOS SANTOS; MATAI, 2010).

A exploração do xisto é discutida em diversas regiões do planeta, como uma opção viável frente à constatação da vulnerabilidade da oferta de petróleo. Os Estados Unidos sinalizam para o fato de que haverá, no futuro, uma queda vertiginosa na produção mundial de petróleo, com o decorrente aumento na necessidade de novas fontes de combustíveis, sejam elas não convencionais fósseis (areias oleosas, petróleo de águas ultra profundas, óleo de xisto) ou não convencionais renováveis (biocombustíveis) (DOS SANTOS; MATAI, 2010).

Com base nesse argumento, avalia-se a utilização das tecnologias de backstop, como é o caso da extração de óleo a partir do xisto, mesmo em face de seu elevado custo. O primeiro ponto a ser apreciado, nesse caso, é a viabilidade econômica do investimento. Para Dos Santos e Matai (2010), a relação custo-benefício do gás de xisto somente é vantajosa, em termos econômicos, em situações nas quais o preço do barril de petróleo atinge algo em torno de US\$150,00 (cento e cinquenta dólares), como ocorreu no primeiro semestre de 2008.

O outro ponto a ser analisado é a viabilidade ambiental do empreendimento. Na década de 80, os impactos ambientais apontados para a exploração do xisto resultam da mineração a céu aberto, bem como dos rejeitos do processo de extração do óleo da rocha e do tratamento para a obtenção dos produtos desejados. Essa técnica foi substituída pelo fraturamento hidráulico ou fracking, que consiste na injeção, sob uma determinada pressão, de uma mistura composta por água, areia e detergentes com a finalidade de fraturar a rocha, liberando assim o gás de xisto que nela está contido (AHMED, 2013).

A filosofia da valoração de rejeitos de processo originou novas tecnologias capazes de promover a utilização dos rejeitos do processo de produção de óleo de xisto para a recomposição do solo minerado e como matéria prima para outros processos produtivos. A utilização dos três principais rejeitos desse processo passa a ser feita da seguinte maneira: a) os finos de xisto prestamse à geração de eletricidade via caldeiras de leito fluidizado; b) o "xisto retortado" passa a ser utilizado como matéria prima nas indústrias de cimento e cerâmica; c) e os efluentes líquidos (águas de xisto), apresentam potencial para atuar como corretores de pH do solo, para além do cal-xisto, já amplamente utilizado na agricultura. Essa valoração dos rejeitos produzidos vem aumentar o valor da relação entre receita e custos, na exploração do xisto (DOS SANTOS; MATAI, 2010). 
Ocorre que, mesmo diante das importantes inovações acima, a viabilidade ambiental da industrialização do xisto continua representando um fator bastante restritivo, haja vista os altos custos envolvidos com a mitigação dos impactos causados pelo processo de mineração. Isto sem falar na necessidade de grandes extensões de terra para fins de mineração, o que ocasiona um impasse entre a população local e a empresa exploradora. Em contrapartida, figuram entre os benefícios os aspectos econômicos decorrentes da construção de um polo de desenvolvimento regional, a geração de empregos e o aumento das receitas municipais, além das melhorias na infraestrutura local (DOS SANTOS; MATAI, 2010).

Há, por fim, uma outra preocupação bastante pertinente, que vai além da questão da escassez do petróleo e da viabilidade econômica e ambiental do investimento: a fragilidade do cenário geopolítico do petróleo. Como se sabe, a maior parte da oferta de petróleo, no globo terrestre, encontra-se situada em países de forte instabilidade política, como é o caso do Golfo Pérsico, da Rússia ou dos países do Golfo da Guiné. Isto resulta em uma inegável vulnerabilidade do sistema de energia mundial. Com essa motivação, países como os Estados Unidos, a Austrália, a Jordânia, a África do Sul e o Marrocos, detentores de recursos de xisto até então classificados como estratégicos ou não viáveis economicamente, têm investido em estudos técnicos e econômicos voltados para uma possível produção de óleo de xisto (DOS SANTOS; MATAI, 2010).

No caso dos Estados Unidos da América (EUA), o desenvolvimento da indústria do xisto presta-se ainda a evitar a importação de energia, equilibrar a balança comercial e, por via de consequência, a evasão de divisas. Lá, a exploração já é uma realidade, assim como também o são seus resultados. O Jornal O Globo, em matéria publicada no dia 09 de outubro de $2013^{4}$, noticia que, após a exploração do xisto nos EUA, moradores das regiões exploradas afirmam observar alterações na qualidade da água e do ar, diminuição da produção de frutos e, ainda, o aumento da taxa de mortalidade de animais.

Por esse motivo, alguns Condados, como Maryland e Nova York, optaram por vetar a atividade, a despeito de a indústria local refutar ou minimizar os referidos relatos. O Jornal afirma ainda que o governo dos EUA admite a ocorrência de vazamentos de gás metano em razão da exploração dessa fonte de energia não renovável, por meio do processo denominado "fracking" (ou fracionamento hidráulico).

\footnotetext{
${ }^{4}$ BARBOSA, Flávia. Gás de xisto: custo ambiental é o maior desafio. [online] Disponível na Internet via WWW. URL: https://oglobo.globo.com/economia/gas-de-xisto-custo-ambiental-o-maior-desafio-10304857. Acesso em: 15 mai. 2018.
} 
Com isso, discute-se, no cenário americano, a possibilidade da criação de novas regras, capazes de elevar o custo da atividade ou até mesmo inviabilizar a referida exploração do meio ambiente. Por essa mesma lógica, e em prol da preservação do meio ambiente, vários países europeus, como a China e a Índia, já determinam a inviabilidade de expansão do gás de xisto por motivos de risco ambiental. Ademais, há estudos publicados na revista Nature, de autoria de David King, ex-consultor científico do governo britânico, que esclarecem que o rendimento de um poço de gás de xisto encontra-se fadado a diminuir de $60 \%$ a $90 \%$ após seu primeiro ano de exploração (AHMED, 2013).

As maiores reservas de xisto do Brasil estão situadas no Paraná, Mato Grosso, sul de Goiás, sudoeste de Minas Gerais, centro-leste de São Paulo e ao longo do segundo planalto Paranaense onde já existe uma área de mineração da Petrobras, em São Mateus do Sul, no Paraná (EMBRAPA https://www.embrapa.br/busca-de-noticias/-/noticia/2320581/projeto-xisto-agricola-completadez-anos).

A exploração dá-se por meio da tecnologia "Petrosix ${ }^{\circledR ”}$, criada e patenteada pela Petrobras, que viabiliza a geração de óleo combustível, nafta, gás combustível, gás liquefeito e enxofre, e outros insumos para pavimentação, utilizados pelos mais diversos segmentos industriais (cerâmica, refinaria de petróleo, cimenteira, usinas de açúcar e agricultura). A Petrobras conta com duas unidades de produção, uma inaugurada em 1972 e outra com início da operação em dezembro de 1991, e o principal mercado consumidor é o próprio Estado do Paraná, além de Santa Catarina, São Paulo e Rio Grande do Sul (PETROBRAS - http://www.petrobras.com.br/pt/nossasatividades/principais-operacoes/refinarias/unidade-de-industrializacao-do-xisto-six.htm).

Contudo, a tecnologia e o processo de mineração empregados na indústria do xisto vêm prejudicando o meio ambiente e a saúde humana no município. Por esse motivo, a Promotoria de Justiça de São Mateus do Sul ajuizou ação civil pública requerendo à Justiça a interdição da Petróleo Brasileiro S/A SIX (Superintendência da Industrialização do Xisto). A ação resulta de investigação iniciada pelo Ministério Público do Paraná (MP-PR) no ano 2000, com o escopo de averiguar as condições ambientais da unidade de extração de xisto, haja vista reclamações de moradores pertinentes à qualidade do ar nas proximidades das usinas.

Foi então realizada perícia no local, elaborada por profissional perito da Universidade de São Paulo, na qual resta consignada a emissão de poluentes atmosféricos por parte da Petrosix, além de concentrações de mercúrio no leito acima do permitido em lei, o que resulta no comprometimento da saúde dos moradores de São Mateus do Sul e de funcionários da empresa requerida. Por esse motivo, no pedido, o MP-PR requereu a interdição imediata do empreendimento, a condenação da 
empresa ao pagamento de indenização pelo dano moral ambiental e a reparação dos danos causados ao meio ambiente e à saúde pública.

Atualmente, na contramão do ocorrido em São Mateus do Sul, no Paraná, e nos países que vêm declinando a industrialização do xisto, por sua inviabilidade econômica e ambiental, conforme acima explicitado, o Brasil decidiu promover rodadas de licitações públicas para a concessão ou partilha de produção para a exploração do xisto, por intermédio da Agência Nacional de Petróleo (ANP).

\section{AS RODADAS DE LICITAÇÕES PARA A EXPLORAÇÃO DO GÁS DE XISTO NO BRASIL}

No Brasil, a Lei n.o 9.478/97 criou o Conselho Nacional de Política Energética - CNPE, órgão vinculado à Presidência da República e presidido pelo Ministro de Estado de Minas e Energia, atribuindo-lhe a função de propor ao Presidente da República políticas nacionais e medidas específicas ${ }^{5}$ destinadas ao aproveitamento racional dos recursos energéticos do País ${ }^{6}$, a definição de estratégia e a política de desenvolvimento econômico e tecnológico da indústria de petróleo, de gás natural, de outros hidrocarbonetos fluidos e de biocombustíveis ${ }^{7}$, dentre outras atribuições. Ainda, incumbe ao CNPE definir, em território nacional, os blocos a serem objeto de concessão ou partilha de produção ${ }^{8}$ para a exploração de gás natural, petróleo e outros insumos energéticos, sendo atribuição da Agência Nacional do Petróleo - ANP a elaboração dos editais e a promoção das licitações para a respectiva concessão de exploração, desenvolvimento e produção ${ }^{9}$.

Nesse contexto, e a partir da Resolução CNPE n. 06/2013, publicada no Diário Oficial da União, em 07 de agosto de 2013, foi autorizada a deflagração da 12a Rodada de Licitações da ANP, com a oferta de 240 (duzentos e quarenta) blocos para a exploração de insumos energéticos, dentre os quais situa-se o gás de xisto. Trata-se da primeira iniciativa do governo brasileiro pautada na utilização da técnica de faturamento hidráulico em território nacional, uma vez que foram licitadas áreas passíveis de exploração dessa matriz de geração de energia. Na sequência, no dia 28 de novembro de 2013, foi realizada a 12a Rodada de Licitações, pela ANP, tendo sido arrematados 72 blocos com risco exploratório.

\footnotetext{
${ }^{5}$ Art. $2{ }^{\circ}$, caput, da Lei n. 9 9.478/97.

${ }^{6}$ Art. 20 , I da Lei n. $09.478 / 97$.

${ }^{7}$ Art. 2ㅇ, IX da Lei n. $99.478 / 97$.

${ }^{8}$ Art. 2ㅇ, VIII da Lei n. 9 9.478/97.

${ }^{9}$ Art. 8 으, IV da Lei n.o 9.478/97.
} 
Diante desse cenário, o Ministério Público Federal decidiu interpor ações civis públicas questionando a pretendida contratação pública, com o objetivo de suspender os atos do mencionado certame, considerando os riscos ambientais envolvidos e a ausência de estudos preliminares a serem realizados pelos órgãos governamentais competentes. Ademais, a ausência de regulamentação para a exploração do gás de xisto no país e a inobservância do art. 2o, I da Portaria Interministerial n. 198/12 do Ministério de Minas e Energia, o qual estabelece a necessidade de ser realizada a Avaliação Ambiental de Áreas Sedimentares (AAAS) constituem alguns dos fatores que motivaram a judicialização da 12a Rodada de Licitações da ANP, uma vez que, sem a realização de estudos prévios, há incerteza quanto aos riscos relacionados à essa forma de exploração, em território nacional.

Por intermédio da Ação Civil Pública n.o 5005509-18.2014.404.7005, o Tribunal Regional Federal da 4a Região, atendendo ao pedido do Ministério Público Federal do Paraná, anulou os atos praticados na 12a Rodada de Licitações, pertinentes à exploração de gás de xisto na Bacia Hidrográfica do Rio Paraná, bem como os contratos de concessão nas áreas em que foram firmados. Conforme a decisão jurisdicional proferida, no referido processo, pela magistrada Lília Cortes de Carvalho de Martino:

Diante do todo exposto, impossível não reconhecer que o procedimento licitatório ao incluir a possibilidade de exploração de recursos não convencionais nos blocos do setor SPAR-CS da Bacia do Rio Paraná, da forma como realizada, caracteriza afronta ao princípio da precaução, impondo-se a nulidade do certame quanto a esse tocante e, por conseguinte, dos contratos já firmados.

Decisões semelhantes foram exaradas pela Justiça Federal, no sentido de suspender os atos praticados no mencionado procedimento intentado pela ANP, relativamente à Bacia Sergipe-Alagoas (Ação Civil Pública - ACP n.o 0800366-79.2016.4.05.8500) ${ }^{10}$, Bacia do Parnaíba (ACP n.o 000561046.2013.4.01.4003) e Bacia do Recôncavo (ACP n.o 0030652-38.2014.4.01.3300), principalmente, em decorrência da ausência de mecanismos regulatórios para essa atividade, bem como, considerando o parecer técnico negativo emitido pelo Grupo de Trabalho Interinstitucional de Atividades de Exploração e Produção de Óleo e Gás do Ministério do Meio Ambiente (GTPEG), coordenado pelo Instituto Brasileiro de Meio Ambiente e dos Recursos Naturais Renováveis IBAMA; e pela ausência de estudos preliminares, como a Avaliação Ambiental de Áreas Sedimentares

10 Disponível em: < http://www.mpf.mp.br/se/sala-de-imprensa/noticias-se/a-pedido-do-mpf-justicasuspende-exploracao-de-gas-de-xisto-em-sergipe-e-alagoas>. Acesso em 10 Agosto 2017. 
(AAAS), prevista no art. 2으, inciso I, da Portaria Interministerial n.ำ 198/12, do Ministério de Minas e Energia.

Esses conflitos jurídicos também permearam a 13a Rodada de Licitações organizada pela ANP, resultando na suspensão dos efeitos decorrentes do certame por meio da Ação Civil Pública n.으 0800366-79.2016.4.05.8500, mencionada acima, interposta pelo Ministério Público Federal. Nessa perspectiva, vislumbra-se que o Poder Público enfrenta uma forte resistência da sociedade para a implementação de iniciativas relacionadas à exploração do gás de xisto no Brasil, haja vista a inviabilidade ambiental relacionada à prática dessa atividade econômica.

Conforme destacado linhas acima, o Grupo de Trabalho Interinstitucional de Atividades de Exploração e Produção de Óleo e Gás (GTPEG), formado pelo IBAMA, Instituto Chico Mendes de Conservação da Biodiversidade - ICMBio, Ministério do Meio Ambiente - MMA e Agência Nacional de Águas - ANA, desempenha importante papel nesse contexto, tendo inclusive elaborado um relevante instrumento de análise dos impactos da exploração do gás de xisto em território nacional, ao analisar as áreas de exploração ofertadas pela 12a Rodada de Licitações da ANP.

Por meio do Parecer Técnico GTPEG n.ㅇ 03/201311 (2013, p. 53-61), foram relacionadas avaliações técnicas acerca da exploração do gás não convencional no mencionado certame, dentre as quais, a necessidade de "(...) aprofundamento no conhecimento geológico de cada área que se pretende licitar como ponto de partida para todas as avaliações necessárias para a realização da atividade (...)", bem como, que não há estrutura regulatória adequada no país capaz de executar o controle dos riscos da atividade e a imprescindibilidade da Avaliação Ambiental de Área Sedimentar - AAAS, "por sua característica de ampla participação pública". Na conclusão do estudo foi mencionado, pelo GTPEG (2013, p. 56), o seguinte:

No que diz respeito à exploração de gás não convencional, o GTPEG entende não haver elementos suficientes para uma tomada de decisão informada sobre o assunto. É preciso intensificar o debate na sociedade brasileira sobre os impactos e riscos ambientais envolvidos nessa exploração e avançar na regulamentação e protocolos para atuação segura. Recomenda-se a adoção da Avaliação Ambiental de Área Sedimentar - AAAS como um dos instrumentos adequados à definição das condições de contorno para utilização das técnicas de faturamento hidráulico em poços horizontais nas bacias de interesse.

\footnotetext{
${ }^{11}$ Disponível em: < http://www.brasil-rounds.gov.br/arquivos/Diretrizes_Ambientais_GTPEG_12a_Rodada/ Parecer/Parecer_GTPEG_R12.pdf. Acesso em: 25 Setembro de 2017.
} 
Os procedimentos subsequentes da ANP para a exploração de petróleo e gás natural estão sendo monitorados por movimentos sociais, instituições não governamentais e pelos legitimados à defesa do meio ambiente, previstos na Lei n.ำ 7.347/85, especialmente, o Ministério Público Federal. Inobstante, não houve vedação expressa à utilização da técnica de fraturamento hidráulico na 14a12 e $15^{13}{ }^{13}$ Rodadas de Licitações, organizadas pela ANP, apesar de não estar prevista, do mesmo modo, no edital, a utilização de técnicas não convencionais de extração de gás natural.

\section{ANÁLISE DAS PROPOSTAS GOVERNAMENTAIS PARA A EXPLORAÇÃO DO GÁS DE XISTO}

A iniciativa verificada por meio dos leilões da Agência Nacional do Petróleo - ANP, de incentivar a produção do gás de xisto no Brasil decorre dos objetivos da União de diversificar a matriz energética no país por meio da exploração de fontes renováveis e não renováveis de geração de energia elétrica e alcançar a almejada segurança energética, com opções para a produção deste insumo em caso de variações nos níveis dos reservatórios, aumento ou redução nos preços das commodities, dentre outros fatores capazes de afetar o abastecimento energético.

O Brasil é um país com amplo potencial de diversificação da matriz energética, ante a disponibilidade, em território nacional, dos principais insumos que são utilizados para a geração de energia, como: biomassa; ventos passíveis de gerar força mecânica para a instalação de usinas eólicas; disponibilidade de petróleo e gás natural em subsolo; áreas agricultáveis para o plantio da cana de açúcar e outras matérias primas para a produção de biocombustíveis; presença de cursos d'água para a geração hidráulica; uma das maiores reservas de urânio do planeta; elevada incidência de radiação solar; dentre outros insumos de menor capacidade de aproveitamento.

Embora a matriz energética brasileira seja considerada limpa, principalmente, em virtude das grandes hidrelétricas instaladas em território nacional, as quais são responsáveis pela geração de $60,95 \%$ da energia elétrica consumida ${ }^{14}$ e apesar da elevada capacidade do país para a exploração de fontes renováveis, especialmente, por meio da geração fotovoltaica e eólica, verifica-se que as políticas públicas do setor de energia no Brasil continuam sendo prioritariamente direcionadas para os investimentos em fontes não renováveis, principalmente, por meio da geração termelétrica, com

\footnotetext{
12 Realizada pela Agência Nacional do Petróleo em 27 de setembro de 2017.

${ }^{13}$ Realizada pela Agência Nacional do Petróleo em 29 de março de 2018.

${ }^{14}$ Disponível em: <http://www2.aneel.gov.br/aplicacoes/capacidadebrasil/capacidadebrasil.cfm>. Acesso em: 19 Agosto de 2017.
} 
a utilização de combustíveis fósseis como o petróleo, o gás natural e, mais recentemente, o gás de xisto.

Diante do amplo potencial energético do país, se faz necessária a realização de estudos técnicos para a definição das alternativas de geração de energia elétrica a serem exploradas, que levem em consideração a variável relacionada ao custo de produção e a disponibilidade do insumo, mas também, que ocasionem o menor impacto ambiental e social, possibilitando uma forma de desenvolvimento no setor de energia que seja sustentável, em longo prazo.

Conforme preleciona Marinho (2008, p. 263), as crescentes restrições ambientais e as inquestionáveis evidências de radicais mudanças climáticas no planeta impõem novas atitudes diante do desperdício, em curto e em longo prazo. Há necessidade de políticas que promovam o uso eficiente dos recursos naturais, de modo a se assegurar a expansão da oferta e a diversificação da matriz energética, mediante alternativas ambientalmente sustentáveis.

Apesar da matriz energética brasileira ser sedimentada na geração hidráulica, segundo Leite (2011, p. 201), instalou-se uma controvérsia no país e no exterior sobre o aproveitamento desse insumo, situando-se de um lado os defensores desse aproveitamento como forma de manter o Brasil na posição de destaque que ocupa quanto à proporção de energia renovável na geração de eletricidade e, de outro lado, aqueles que atribuem prioridade aos aspectos sociais negativos para as populações ribeirinhas afetadas e aos danos causados ao meio ambiente pela mudança no regime dos rios e pela inundação da floresta, sendo o debate público acerca do tema dominado por posição emocional e/ou ideológica.

Verifica-se que ao longo dos anos vem ocorrendo uma gradual redução da participação da geração hidráulica na matriz energética nacional, embora haja grande potencial exploratório dessa energia renovável em virtude da existência de cursos d'água, especialmente, na Região Amazônica. Contudo, a ocorrência de problemas na internalização dos custos ambientais e sociais nos recentes projetos e a imagem negativa perante a opinião pública em torno dos projetos hidrelétricos na Amazônia têm desestimulado essas iniciativas, resultando no crescimento da geração térmica no país, o qual também é motivado pelo fato do governo brasileiro ser um dos maiores produtores de petróleo do mundo ${ }^{15}$.

A substituição da energia hidráulica pela térmica, segundo Trennepohl e Trennepohl (2016, p. 245) ocasionam impactos ambientais de grande amplitude e potencialmente lesivos à economia pública, tanto em relação às perdas financeiras, uma vez que a produção termoelétrica é mais

\footnotetext{
15 Por meio da sociedade de economia mista Petróleo Brasileiro S.A. - Petrobras, criada pela Lei n. 02.004 de 03 de outubro de 1953, que tem a União como acionista majoritária.
} 
dispendiosa, quanto pelos riscos ambientais relacionados a essa atividade, em virtude do aumento na emissão de $\mathrm{CO} 2$ e outros gases responsáveis pelo efeito estufa e pelo aquecimento global.

Em sentido contrário em relação aos custos dos projetos térmicos, Bronzatti e Neto (2008, p. 12) afirmam que além do potencial de produção e a probabilidade de crescimento das reservas, o aspecto de custo também tem grande influência na composição da matriz energética de um país e, portanto, no balanço energético, sendo indiscutível que o Petróleo é uma das fontes mais versáteis e de menor custo de produção, logo, investimentos em petróleo devem continuar e as novas descobertas e inovações tecnológicas na exploração em alto mar poderão incrementar a capacidade produtiva de petróleo e, também, do gás natural.

Apesar das controvérsias em relação ao custo, mas considerando a versatilidade da geração térmica, o governo brasileiro pretende aumentar a presença do gás natural, no qual resta incluso o gás de xisto, em seu balanço energético. Nesse sentido há uma tendência ao incentivo à industrialização do xisto em virtude das reservas existentes. Entretanto, diante dos impactos sociais e ambientais ocasionados a partir da exploração desse insumo, especialmente, nos Estados Unidos, bem como, da mobilização social que envolve o tema, ocorrida a partir das Rodadas de Licitações da ANP e da ausência de regulamentações específicas, vislumbra-se que as iniciativas de exploração não oferecem a segurança jurídica necessária aos empreendedores e à sociedade como um todo.

Relativamente à regulamentação do insumo, no Estado do Paraná foi aprovada a Lei n.응 18.947/16, a qual é considerada o primeiro instrumento normativo no país que estabelece regras para a exploração do gás de xisto, sendo previstos requisitos específicos para a execução da atividade econômica como a exigência de Estudo de Impacto Ambiental e Relatório de Impacto Ambiental ${ }^{16}$, apresentação de poços de monitoramento do lençol freático localizado no entorno dos poços de

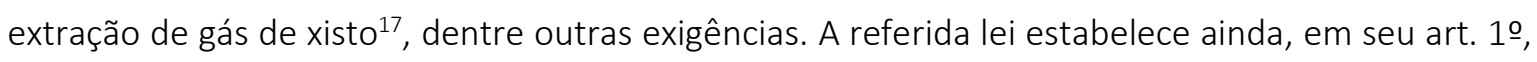
uma suspensão pelo prazo de dez anos dos procedimentos de licenciamento ou autorização para a exploração de gás de xisto no Estado do Paraná, reconhecendo os riscos ambientais ocasionados pela atividade e a ausência de tecnologia que seja capaz de mitigar os impactos decorrentes da técnica de faturamento hidráulico.

O ato normativo em questão veio atender aos anseios expressados nas manifestações sociais decorrentes das licitações da ANP, uma vez que a atuação estatal por meio desses procedimentos demonstrava absoluto descompasso com a necessidade de discussão dos impactos ambientais e sociais decorrentes da atividade, diante da inexistência de estudos preliminares e da ausência do

\footnotetext{
${ }^{16}$ Art. 2으, I da Lei n.o 18.947/16.

${ }^{17}$ Art. 2ㅇ, V da Lei n. 0 18.947/16.
} 
debate social, os quais são fundamentais para o exercício de atividades econômicas potencialmente poluidoras, como é o caso da produção de gás de xisto.

Em nível federal, pretende-se a regulamentação da exploração energética de gás de xisto no Brasil por intermédio do Projeto de Lei no 6.904/2013 proposto pelo Deputado Sarney Filho do Partido Verde do Estado do Maranhão - PV/MA ${ }^{18}$, em trâmite na Câmara dos Deputados, o qual prevê a suspensão por cinco anos das autorizações para a exploração do insumo energético (art. 2º), período em que o Poder Público deverá promover estudos para atualizar a tecnologia de exploração do gás de folhelho de modo que seja ambientalmente sustentável e garanta a segurança dos trabalhadores que atuam na atividade (inciso III), dentre outras obrigações.

Em apenso à mencionada proposta legislativa, também tramita no Congresso Nacional o Projeto de Lei n. 4.118/2015, de autoria do Deputado Marcelo Belinati do Partido Progressista do Estado do Paraná - PP/PR ${ }^{19}$, pelo qual propõe-se o acréscimo do inciso III ao art. 37 do Decreto-Lei no 227, de 28 de fevereiro de 1967, para proibir a outorga de concessão de lavra para exploração de gás mediante processo de fraturação hidráulica ou fracking.

Por uma análise dos mencionados projetos, verifica-se que as proposições de regulamentação elaboradas no âmbito do Poder Legislativo consideram a necessidade de avaliação de impactos ambientais e sociais diante das tecnologias disponíveis para a exploração do gás de xisto, bem como impõe a necessidade de suspensão temporária da exploração da atividade em território nacional diante do reconhecimento da necessidade de serem realizadas pesquisas capazes de identificar os procedimentos que deverão ser adotados, a fim de que propiciem o tratamento das externalidades negativas da industrialização do xisto.

\section{A EXPLORAÇÃO DO GÁS DE XISTO COMO ALTERNATIVA ENERGÉTICA E O DESENVOLVIMENTO SUSTENTÁVEL NO BRASIL}

O legislador constituinte brasileiro, por meio de diversos dispositivos, como o art. 170 e 225, direcionou o desenvolvimento de ações dos segmentos produtivos que atuam no país para a preservação dos elementos que compõem o ambiente, dentro de um viés antropocêntrico alargado que, conforme Leite e Ayala (2011, p. 05), visa a abranger a tutela do meio ambiente

\footnotetext{
18 Disponível em: < http://www.camara.gov.br/proposicoesWeb/fichadetramitacao?idProposicao=603565> . Acesso em: 21 Agosto de 2017.

${ }^{19}$ Disponível em: < http://www.camara.gov.br/proposicoesWeb/fichadetramitacao?idProposicao=2075701>. Acesso em: 21 Agosto de 2017.
} 
independentemente da sua utilidade direta "e busca a preservação da capacidade funcional do patrimônio natural, com ideais éticos de colaboração e interação".

No desenvolvimento de atividades econômicas, como no caso da exploração do gás de xisto, a apropriação dos bens da natureza deve ocorrer de modo ético, ou seja, buscando-se a melhor alternativa tecnológica disponível, com o menor custo, sem descuidar dos estudos ambientais necessários, dentre outras medidas de prevenção. Com isso, o exercício de atividade potencialmente poluidora resta condicionado ao gerenciamento dos riscos ambientais, de forma a assegurar ao homem a fruição do direito fundamental ao meio ambiente ecologicamente equilibrado.

O desenvolvimento de projetos de exploração de gás de xisto no Brasil deve contemplar a incorporação de critérios de sustentabilidade, sob pena da absoluta incompatibilidade constitucional de tais iniciativas, de modo que o objetivo primordial não seja somente a geração de riquezas, com prejuízo para a necessidade de controle dos riscos ambientais e da promoção da justiça social. Por outro lado, diante do potencial de geração de energia e da diversidade da matriz energética existente no país, e considerando os impactos relacionados ao fraturamento hidráulico, cabe ao Poder Público analisar se existem outras formas de garantir a almejada segurança energética, até que sejam estabelecidas novas tecnologias que possibilitem um gerenciamento adequado e seguro dos riscos ambientais atrelados ao fracking.

Diante das denominadas "moratórias" para a exploração do gás de xisto no Brasil, conforme o previsto no projeto de Lei no 6.904/2013, proposto pelo Dep. Sarney Filho do PV/MA, e na Lei n.으 18.947/16, do Estado do Paraná, releva proceder, no presente trabalho, a uma abordagem acerca do gerenciamento dos riscos na implementação da exploração energética do xisto, uma vez que a constitucionalização do direito difuso e intergeracional ao meio ambiente ecologicamente equilibrado não admite a "privatização de lucros e socialização de perdas", segundo Peixoto (2013, p.42).

\subsection{Aspectos jurídicos do gerenciamento de riscos na exploração de gás de xisto}

A experiência acumulada na exploração do gás de xisto nos Estados Unidos da América demonstra um elevado potencial de ocorrência de significativos impactos ambientais, principalmente, em relação às águas subterrâneas. Segundo Heusman e Kellogg (2015, p. 39), analisando os impactos naquele país, os cientistas continuam preocupados com uma série de danos ambientais causados pela técnica de fraturamento hidráulico. Todavia, não houve a manutenção da 
coleta de dados a partir do boom da extração, o que ocasiona uma grande dose de incerteza quanto à poluição proveniente do fracking ${ }^{20}$.

A legislação ambiental brasileira, que possui como fundamento central o art. $225 \mathrm{da}$ Constituição da República de 1988, foi formada de modo a se estabelecer o controle direto pelo Estado de toda e qualquer atividade potencialmente poluidora em território nacional, a partir da definição de requisitos e condicionantes a serem cumpridas, sob pena de responsabilização. Ao Poder Público foi conferido o poder-dever de, inclusive, negar autorização para a prática de determinada atividade se, a partir dos estudos e análises ambientais prévias, restar demonstrado que o equilíbrio ecológico poderá ser comprometido e, com isso, fulminado o mínimo existencial relacionado ao direito ao meio ambiente ecologicamente equilibrado.

O desenvolvimento de uma noção de mínimo existencial ecológico enquanto resultado de uma composição de posições jurídicas e de realidades (subjetiva e objetiva) atinentes ao direito fundamental em questão está relacionado à consideração de padrões de proteção ambiental mínima perante riscos existenciais que podem ser considerados intoleráveis ou inaceitáveis (AYALA, 2011, p. 1049-1050). Ao direito incumbe a atribuição de regular conflitos sociais e ao empreendedor, o ônus de provar que a atividade econômica a ser implementada não ocasiona impactos ambientais ou, ao menos, que estes podem ser compensados ou mitigados. De toda sorte, quando se tratam de conflitos relacionados à fruição do direito fundamental ao meio ambiente ecologicamente equilibrado, deve ser observado sempre um padrão mínimo estabelecido por lei para a proteção de elementos do meio ambiente.

Conforme alerta Carvalho (2011, p. 126), com a importante institucionalização do meio ambiente como um direito fundamental, surge então a necessidade de analisar as estruturas competentes para a tarefa não apenas de reparar e controlar danos, mas também de gerenciar riscos que tenham a capacidade de atingir os interesses juridicamente tutelados das atuais e futuras gerações, de modo que a formação de uma comunicação do risco ambiental, assumida constitucionalmente, seja um processo de racionalização das incertezas.

O controle dos danos e o gerenciamento de riscos deve ser desencadeado pelo empreendedor e promovido e fiscalizado pelo Poder Público, com o escopo de garantir a manutenção de um mínimo existencial ecológico. Se, por um lado, o legislador pátrio não criou uma vedação expressa ao exercício de atividades que resultam em danos ambientais, por outro, fica o

\footnotetext{
${ }^{20}$ No original: "(..) scientists remain concerned about a number of environmental damages caused by fracking. Unfortunately, data collection has not kept pace with the boom in extraction, and a great deal of uncertainty remains regarding pollution from fracking."
} 
empreendedor obrigado, em casos como o da industrialização do xisto, a adotar medidas de prevenção que mitiguem os impactos ambientais.

A partir do reconhecimento da existência de incertezas em relação aos danos ambientais que podem ser ocasionados por meio da técnica de fraturamento hidráulico, há, conforme o Parecer Técnico GTPEG n. 03/2013, um direcionamento invariável do Poder Público para a adoção de atos de prevenção ambiental, pois “(...) a incerteza científica milita a favor do meio ambiente, carregandose ao interessado o ônus de provar que as intervenções pretendidas não trarão consequências indesejadas ao meio considerado" (MILARÉ, 2011, p. 396).

No âmbito jurídico brasileiro, contudo, a ausência de mecanismos de regulação para o gerenciamento de riscos na atividade de exploração de gás de xisto conduz a um cenário de insegurança jurídica. Com efeito, é preciso superar a ausência de critérios ambientais suficientemente definidos, para que seja realizada a implementação bem sucedida do fraturamento hidráulico no país. Até hoje, o que há são apenas estudos prévios voltados precipuamente para a identificação dos campos exploratórios em território nacional, com previsão de utilização de métodos não convencionais para a extração de gás natural, o que se presumo da análise da 12a e 13a Rodada de Licitações da ANP.

Nesse sentido, com base no princípio da prevenção, devem ser estabelecidos padrões de controle ambiental para a exploração de gás de xisto no país, por ser atividade com elevado potencial de danos. Uma das providências do Poder Público a serem implementadas, para o gerenciamento dos riscos ambientais, é a definição dos critérios para o licenciamento ambiental ${ }^{21}$, de forma a permitir a ampla participação popular na tomada de decisão sobre a atividade exploratória.

A Resolução CONAMA n.o 01/86 estabelece um rol exemplificativo de obras e atividades modificadoras do meio ambiente, em que se exige a realização de Estudo de Impacto Ambiental (EIA) e Relatório de Impacto Ambiental (RIMA). No caso em estudo, diante dos custos sociais e ambientais em questão, é primordial que a elaboração dessa tipologia de estudo ambiental seja feita em conjunto com uma ampla participação social, por meio de audiências públicas.

A realização das audiências públicas com a consequente publicidade do EIA/RIMA, comenta Machado (2007, p. 257), possui uma dupla finalidade: o órgão público presta informações ao público; e o público repassa informações à Administração Pública. Ora, se não está prevista, na Resolução CONAMA n. 9 9/87, a exposição da equipe multidisciplinar que elaborou o estudo e do proponente

\footnotetext{
${ }^{21}$ Conforme o art. 8ㅇ, I da Lei n. 6.938/81, compete ao Conselho Estadual do Meio Ambiente - CONAMA estabelecer, mediante proposta do IBAMA, normas e critérios para o licenciamento de atividades efetivas ou potencialmente poluidoras, a ser concedido pelos Estados e supervisionados pelo IBAMA.
} 
do projeto ou empreendedor, é preciso considerar que também não há referência alguma à proibição de manifestação popular nessa etapa do licenciamento ambiental.

Após as audiências públicas, nos termos do art. 5 da Resolução CONAMA n.o 9/8722, o órgão licenciador poderá ou não aprovar o projeto. Logo, é possível concluir que a realização das rodadas de licitações pela ANP não garante que a exploração do gás de xisto será aprovada pelo órgão ambiental, apesar da pressão econômica e política que é exercida sobre os agentes públicos responsáveis pelo licenciamento. Isso tem resultado em um crescente protagonismo do Ministério Público para a tutela do meio ambiente, mediante a responsabilização cível e criminal pela ocorrência de danos ambientais.

Em termos de gerenciamento de riscos ambientais na exploração do gás de xisto, a racionalização das incertezas somente pode ser alcançada mediante a análise de viabilidade por meio da realização dos estudos ambientais prévios. A mera existência de reservas de gás natural e a necessidade de geração energética suplementar em território nacional não justifica a adoção de atos pelo Poder Público que redundem no exercício dessa atividade sem um processo eficaz de gerenciamento de riscos, capaz de promover a adequada preservação dos elementos do meio ambiente.

\subsection{O desenvolvimento sustentável como requisito à exploração energética do gás de xisto no Brasil}

Um importante princípio da ordem econômica, conforme o previsto no art. 170, VI da Constituição da República de 1988, é a defesa do meio ambiente, que direciona as atividades geradoras de riqueza para um padrão de desenvolvimento voltado para a proteção dos elementos do meio ambiente como componente obrigatório, conferindo o atributo da civilidade ambiental às ações tendentes ao progresso civilizatório desencadeado em território nacional, resultando na integração entre a proteção do meio ambiente, o bem estar social e o desenvolvimento econômico, ao que se denomina desenvolvimento sustentável.

Conforme Santos e Freitas (2017, p. 14), no que diz respeito ao art. 170, VI, o legislador constituinte reservou um espaço específico para a proteção ambiental no capítulo que trata dos princípios gerais da atividade econômica, demonstrando que o exercício de atividade destinada à geração de riquezas no país está condicionado ao uso sustentável dos recursos naturais e à

\footnotetext{
${ }^{22}$ Está previsto no art. 5 da Resolução CONAMA n.o 09/87 que "A ata da(s) audiência(s) pública(s) e seus anexos, servirão de base, juntamente com o RIMA, para a análise e parecer final do licenciador quanto à aprovação ou não do projeto".
} 
manutenção de um processo que assegure o devido tratamento dos impactos ambientais resultantes do produto ou serviço.

Derani (2008, p. 224) afirma que a concretização de uma qualidade de vida satisfatória capaz de atingir toda a sociedade está diretamente relacionada ao modo como esta sociedade dispõe da apreensão e transformação de seus recursos, ou seja, de como desenvolve a sua atividade econômica, conduzindo a indagação do conteúdo daquilo que se resume como desenvolvimento econômico.

Assim, com o objetivo de alcançar o almejado desenvolvimento sustentável previsto constitucionalmente, os atos tendentes à exploração de atividade econômica em território nacional devem estar harmonizados com o princípio da proteção do meio ambiente. Quando o Poder Público estabelece tais atos, como no caso das rodadas de licitações da ANP, essa harmonização torna-se ainda mais relevante, considerando o conjunto de prescrições constitucionais e os meios disponíveis ao Estado para a concretização normativa (função positiva ou prestacional).

Cerquinho $(2011,301)$ elucida, nesse mesmo sentido, que independentemente do ato administrativo proposto pela Administração Pública evidenciar absoluta adequação jurídica e lógica entre os seus motivos, conteúdo e fim de interesse público, além da licitude do objeto, caso venha a fulminar a necessidade de preservação do meio ambiente, deverá prevalecer essa última finalidade, não sendo emanado o ato proposto ou, se for o caso, procedendo-se à sua anulação pelo Poder Judiciário, que também pode condenar o administrador a abster-se de praticar o ato.

A previsão do direito fundamental intergeracional ao meio ambiente ecologicamente equilibrado não pressupõe a absoluta impossibilidade de se executar atividades que importem em riscos ambientais, pois do mesmo modo, há um direito fundamental ao desenvolvimento econômico previsto constitucionalmente, que axiologicamente orienta para a valorização do trabalho e da livre iniciativa, e está vinculado à existência digna do ser humano.

Com o objetivo de se evitar a antinomia constitucional e de possibilitar a materialização desse direito ao desenvolvimento, foram criados instrumentos legais, dentre os quais, o previsto no art. 225, IV da Constituição da República de 1988, que impõe ao Poder Público a exigência de estudo prévio de impacto ambiental, a ser apresentado em processo de licenciamento ambiental, para a instalação de obra ou atividade potencialmente causadora de significativa degradação ao meio ambiente.

O desenvolvimento de atividade econômica, nesse sentido, deve considerar os elementos que compõem o meio ambiente, conduzindo a sociedade a um modelo que seja sustentável e que vise ao aproveitamento eficiente dos recursos naturais. Assim, merece ser destacado que o 
legislador da Constituição de 1988 atribui diversas obrigações específicas ao Poder Público no § 1o do art. 225, compreendendo o elevado potencial de transformação social e de concretização do direito ao meio ambiente ecologicamente equilibrado a partir de atos da Administração Pública.

Silva $(2013$, p. 27) leciona que o desenvolvimento econômico e o meio ambiente constituem dois valores aparentemente em conflito, que a Constituição de 1988 alberga. Ambos, devem ser concretizados no interesse do bem estar e da boa qualidade de vida aos brasileiros, de modo que o desenvolvimento sustentável representa a conciliação desses dois valores: uma exploração equilibrada dos recursos naturais, nos limites da satisfação das necessidades e do bem estar da presente geração, sem descuidar de sua necessária conservação, com foco nas futuras gerações.

Deste modo, a realização de rodadas de licitação por meio da ANP, em que se permite ao empreendedor, inclusive estrangeiro, a exploração não convencional de gás natural em território nacional, sem a existência prévia de uma regulamentação específica, que promova o gerenciamento de riscos ambientais e conduza ao desenvolvimento sustentável, apresenta-se de todo dissonante da finalidade formalmente estabelecida na Constituição, e que deve ser concretizada, especialmente, pelos órgãos que compõem a Administração Pública.

A partir da Constituição de 1988, um dos objetivos do Poder Público, em relação à geração de energia elétrica, deve ser a implementação em território nacional de uma matriz energética sustentável. Com isso, privilegia-se a geração de energia por meio de fontes renováveis e incentivase a eficiência energética, de modo que processos de geração energética potencialmente causadores de significativa degradação ambiental, como é o caso da geração térmica e dos processos de geração de energia nuclear, tão somente atuem como reforço energético por ocasião de algum estresse hídrico que afete os reservatórios de hidrelétricas, ou nos momentos de baixa geração das usinas eólicas ou solares.

Em abordagem sobre o desenvolvimento sustentável, Sachs (2007, p. 81) menciona que a melhor forma de preservação da natureza consiste no aprendizado das boas formas do seu uso, sendo necessário criar a consciência de que é preciso preservar para continuar a fazer esse uso. incentivo pelo Poder Público ao uso de alternativas energéticas que ocasionam em significativos impactos ambientais, como a exploração do gás de xisto, sem prévia discussão com a sociedade e sem a devida regulamentação dos parâmetros da atividade, a despeito da possibilidade de exploração de outras fontes menos poluidoras, não conduz o país ao almejado desenvolvimento sustentável.

O desenvolvimento sustentável no setor de energia busca-se através da construção de uma matriz energética limpa, por meio da utilização de recursos renováveis, devendo ser esse o objetivo 
principal das políticas públicas direcionadas aos agentes que atuam nesse segmento. Em virtude do aproveitamento intermitente de algumas fontes de geração energética não renováveis, como a solar e a eólica, as alternativas não renováveis de geração ainda serão necessárias por muitas décadas, entretanto, não devem ser o foco principal das políticas públicas no país.

Segundo Silva, Oliveira e Guerra (p. 82), durante os próximos 30-60 anos, os esforços devem ser dirigidos para realizar as oportunidades alinhadas com o progresso tecnológico e a inovação como partes de uma estratégia detalhada que oferece suporte à diversidade de opções de recursos no próximo século. O desafio fundamental para a maioria das opções renováveis, portanto, é o estudo dessa forma de utilizar, de maneira rentável, os recursos renováveis, inerentemente difusos e, em alguns casos, intermitentes.

Há necessidade de construção de uma matriz energética sustentável, sendo esse um dos 17 Objetivos do Desenvolvimento Sustentáve ${ }^{23}$ estabelecidos pela Organização das Nações Unidas ONU, a serem cumpridos até 2030. Do mesmo modo, os acordos globais para a proteção do meio ambiente, como o Acordo de Paris, o qual foi ratificado pelo Governo Brasileiro por meio do Decreto Legislativo n. 140, de 16 de agosto de 2016, exigem a adoção de políticas públicas que considerem a emissão de menos poluentes à atmosfera.

A manutenção de uma matriz energética sustentável no país envolve o direcionamento de políticas públicas que não levem em consideração tão somente fatores econômicos, capazes de incentivar o aproveitamento de fontes energéticas renováveis. Assim, para que se proceda ao aproveitamento do gás de xisto em território nacional, diante dos impactos ambientais amplamente observados pela comunidade científica, há que se formular, primeiramente, a devida regulamentação. Assim, a demanda energética deverá ser suprida por outras fontes com menor capacidade de ocasionar significativa degradação do meio ambiente, com vistas a consolidar o objetivo fundamental previsto no art. 225 da Constituição da República de 1988, que é a manutenção do meio ambiente ecologicamente equilibrado para as presentes e futuras gerações.

\section{CONSIDERAÇÕES FINAIS}

A disponibilidade do petróleo concentra-se em países de grande instabilidade política, como é o caso do Golfo Pérsico, da Rússia ou dos países do Golfo da Guiné, por esse motivo, discute-se, em nível nacional e internacional, a vulnerabilidade do sistema de energia mundial. Por essa lógica,

${ }^{23}$ ODS 7 - Assegurar o acesso confiável, sustentável, moderno e a preço acessível à energia para todos. 
os países encontram-se voltados para a necessidade de investimentos em fontes renováveis e não renováveis de energia, como é o caso do gás de xisto, haja vista a escassez do petróleo e a questão geopolítica delicada que envolve a sua produção. Por outro lado, a diversificação da matriz energética encontra-se condicionada pela viabilidade econômica e ambiental das novas fontes.

Nessa perspectiva, diversos países como os Estados Unidos, a Austrália, a Jordânia, a África do Sul e o Marrocos vêm investindo na exploração do xisto, por meio de estudos técnicos e econômicos. No Brasil, país de matriz energética diversificada, privilegiado por suas dimensões territoriais, pelo seu clima e pela biodiversidade encontrada em seus diferentes biomas, o Poder Público investiu na concessão ou partilha de produção para a exploração do gás de xisto mediante a técnica de faturamento hidráulico (ou fracking), por meio da promoção de Rodadas de Licitações promovidas pela Agência Nacional do Petróleo.

Na prática, a exploração do gás de xisto se dá, no Brasil, desde 1972, com a inauguração de uma Unidade de Produção, pela Petrobras, no município de São Mateus do Sul, no Paraná. No local, a técnica empregada é a mineração e a consequência observada, a degradação ao meio ambiente, com prejuízo para a saúde dos moradores do município e dos trabalhadores das referidas unidades de produção. Tanto é assim que o assunto foi objeto de apreciação do Judiciário, por intermédio de Ação Civil Pública interposta pelo Ministério Público Estadual competente.

A técnica de fraturamento hidráulico ou fracking apresenta-se como uma solução menos impactante em termos ambientais, e de elevado custo econômico, que agrega valor às externalidades da produção do gás de xisto por meio da valoração de rejeitos de processo para a recomposição do solo minerado e como matéria prima para outros processos produtivos, nas indústrias de cimento e cerâmica.

Todavia, ainda que se argumente que a proposta da Administração Pública é implementar uma técnica mais moderna e ambientalmente viável, com o aproveitamento dos resíduos produzidos, há necessidade de critérios definidores dos procedimentos capazes de salvaguardar o bom uso dos elementos do meio ambiente, de forma a se harmonizar os interesses econômicos com a proteção ambiental constitucionalizada, no Brasil, em 1988.

A realização de Estudos de Impacto Ambiental e Relatório de Impacto Ambiental atinentes à exploração do xisto mostra-se como etapa fundamental ao adequado gerenciamento de riscos dessa atividade. Diante dos impactos ambientais ocasionados na exploração do gás de xisto, especialmente, em reservas localizadas nos Estado Unidos da América, vislumbra-se a necessidade de um amplo debate social que possibilite o conhecimento dos riscos e benefícios que esse tipo de atividade pode proporcionar. 
A judicialização das Rodadas de Licitações vem demonstrando um empoderamento do Ministério Público, que age onde a própria Administração Pública deveria atuar, ainda em nível de planejamento: a promoção e defesa do meio ambiente para as atuais e futuras gerações. Dentre os principais equívocos que vem sendo mencionados pelo Ministério Público nas rodadas de licitação realizadas pela Agência Nacional do Petróleo está a ausência de estudos de viabilidade que indiquem os riscos ambientais e sociais que podem emergir a partir da exploração do gás de xisto.

Verificou-se que o ordenamento jurídico brasileiro ainda não comporta a necessária normatização do gerenciamento de riscos em face do meio ambiente, no que diz respeito à industrialização do xisto. Para tanto, o Poder Público deve obter, primeiramente, o conhecimento necessário, por meio da pesquisa científica, o que deverá viabilizar a definição de procedimentos ambientalmente corretos que viabilizem a exploração dessa fonte energética.

A exploração do gás de xisto no Brasil, diante dos avanços tecnológicos que são necessários para evitar e mitigar os impactos ambientais decorrentes desse tipo de atividade, ainda mostra-se como inviável em larga escala, fazendo-se necessário o investimento tecnológico diante das especificidades dos elementos do meio ambiente no país, o qual possui a maior bacia hidrográfica do planeta, tipologias distintas de solo por região, a maior floresta tropical do planeta, dentre outras características ambientais que devem ser observadas na exploração de potenciais energéticos no país.

Deste modo, deve-se fazer uma reflexão sobre as políticas públicas direcionadas ao setor de energia elétrica no país com vistas à análise racional do modo de produção que vem sendo incentivado pelo Poder Público, para que haja a exploração de potenciais energéticos que importem em menor impacto ambiental e propiciem a geração necessária para o desenvolvimento das atividades econômicas.

\section{REFERÊNCIAS}

AYALA, Patrick de Araújo. Direito fundamental ao ambiente, mínimo existencial ecológico e proibição de retrocesso na ordem constitucional brasileira. In: MILARÉ, Édis; MACHADO, Paulo Affonso Leme (Org.). Doutrinas essenciais de direito ambiental. Vol. I (mar. 2011). p. 1039-1076. São Paulo: Revista dos Tribunais, 2011.

BARBOSA, Flávia. Gás de xisto: custo ambiental é o maior desafio. [online] Disponível na Internet via WWW. URL: https://oglobo.globo.com/economia/gas-de-xisto-custo-ambiental-o-maior-desafio10304857. Acesso em: 15 mai. 2018. 
BRASIL. Agência Nacional de Energia Elétrica. Disponível em: < http://www2.aneel.gov.br /aplicacoes/capacidadebrasil/OperacaoCapacidadeBrasil.cfm>. Acesso em: 04 set. 2017. BRASIL. Câmara dos Deputados. Projeto de Lei n.o 6.904/2013. Estabelece medidas relativas à atividade de exploração de gás de folhelho (também conhecido como xisto). Disponível em: < http://www.camara.gov.br/proposicoesWeb/fichadetramitacao?idProposicao=603565>. Acesso em: 27 set. 2017. Texto Original.

BRASIL. Câmara dos Deputados. Projeto de Lei n.o 4.118/2015. Acrescenta inciso III no art.37 do Decreto-Lei no 227, de 28 de fevereiro de 1967, para proibir a outorga de concessão de lavra para exploração de gás mediante processo de fraturação hidráulica, ou fracking. Disponível em: < http://www.camara.gov.br/proposicoesWeb/fichadetramitacao?id

Proposicao $=2075701>$. Acesso em: 27 set. 2017. Texto Original.

BRASIL. CONAMA. Resolução no 01, de 23 de janeiro de 1986. Dispõe sobre critérios básicos e diretrizes gerais para a avaliação de impacto ambiental. In: Diário Oficial da União, Brasília, 17 de fevereiro, 1986.

BRASIL. CONAMA. Resolução no 09, de 03 de dezembro de 1987. Dispõe sobre a realização de Audiências Públicas no processo de licenciamento ambiental. In: Diário Oficial da União, Brasília, 05 de julho, 1990.

BRASIL. Constituição da República Federativa do Brasil. Brasília: Senado Federal, 1988.

BRASIL. Decreto Legislativo n. 140, de 16 de agosto de 2016. Aprova o texto do Acordo de Paris sob a Convenção-Quadro das Nações Unidas sobre Mudança do Clima - UNFCCC, celebrado em Paris, em 12 de dezembro de 2015, e assinado em Nova York, em 22 de abril de 2016. In: Diário Oficial da União, Brasília, 17 de agosto, 2016.

BRASIL. Lei n.o 6.938 de 31 de agosto de 1981. Dispõe sobre a Política Nacional do Meio Ambiente, seus fins e mecanismos de formulação e aplicação, e dá outras providências. In: Diário Oficial da União, Brasília, 07 de agosto, 1997.

BRASIL. Lei n.o 7.347 de 24 de julho de 1985. Disciplina a ação civil pública de responsabilidade por danos causados ao meio-ambiente, ao consumidor, a bens e direitos de valor artístico, estético, histórico, turístico e paisagístico (VETADO) e dá outras providências. In: Diário Oficial da União, Brasília, 25 de julho, 1985.

BRASIL. Lei n. 9.478 de 06 de agosto de 1997. Dispõe sobre a política energética nacional, as atividades relativas ao monopólio do petróleo, institui o Conselho Nacional de Política Energética e a Agência Nacional do Petróleo e dá outras providências. In: Diário Oficial da União, Brasília, 12 de setembro, 1990. 
BRASIL. Tribunal Regional Federal da 1으 Região. Ação Civil Pública n.ㅇ 0005610-46.2013.4.01.4003. Requerente: Ministério Público Federal. Juiz Brunno Christiano Carvalho Cardoso. Disponível em: <https://www.escavador.com/diarios/516782/TRF1-SJPI/judicial/ 2017-07-24/231059063/movimentacao-do-processo-0005610-4620134014003>. Acesso em: 10 Agosto 2017.

BRASIL. Tribunal Regional Federal da 1으 Região. Ação Civil Pública n.ํ 30652-38.2014.4.01.3300. Requerente: Ministério Público Federal. Juiz Carlos D'avila Teixeira. Disponível em: < https://www.jusbrasil.com.br/diarios/documentos/350881883/andamento-do-processo-n-306523820144013300-acao-civil-publica-17-06-2016-do-trf-1?ref=topic_feed>. Acesso em: 12 Agosto 2017.

BRASIL. Tribunal Regional Federal da 4o Região. Ação Civil Pública n.o 5005509-18.2014.404.7005. Requerente: Ministério Público Federal. Juíza Lília Côrtes de Carvalho de Martino.Disponível em: $<$ https://www2.trf4.jus.br/trf4/controlador.php?acao=consulta_ processual_resultado_pesquisa\&txtValor=5005509-18.2014.4.04.7005\&selOrigem=PR\&chk MostrarBaixados=1\&selForma=NU\&hdnRefld=\&txtPalavraGerada=>. Acesso em: 10 Agosto 2017. PARANÁ (Estado). Lei n. 18.947 de 22 de dezembro de 2016. Dispõe sobre a exploração de gás de xisto, ou gás de folhelho, através do método de perfuração seguido de fraturamento hidráulico (fracking). In: Diário Oficial do Estado, Paraná, 23 de dezembro. 2016.

BRONZATTI, Fabricio Luiz; NETO, Alfredo larozinski. Matrizes energéticas no Brasil: cenário 20102030. In: Encontro nacional de engenharia de produção, XXVIII, 2008, Rio de Janeiro. Anais. Rio de Janeiro: Abepro, 2008. p.1-15. Tema: a integração de cadeias produtivas com a abordagem da manufatura sustentável. Disponível em: <http://www.abepro.org.br/biblioteca/enegep2008_TN_STO_077_541_11890.pdf >. Acesso em: 22 set. 2017.

CARVALHO, Delton Winter de. Sistema constitucional brasileiro de gerenciamento dos riscos ambientais. In: MILARÉ, Édis; MACHADO, Paulo Affonso Leme (Org.). Doutrinas essenciais de direito ambiental. Vol. I (mar. 2011). p. 119-140. São Paulo: Revista dos Tribunais, 2011.

CERQUINHO, Maria Cuervo Silva Vaz. Do impacto ambiental. In: MILARÉ, Édis; MACHADO, Paulo Affonso Leme (Org.). Doutrinas essenciais de direito ambiental. Vol. V. p. 291-325. São Paulo: Revista dos Tribunais, 2011.

DERANI, Cristiane. Direito ambiental econômico. 3. ed. São Paulo: Saraiva, 2008. 
DOS SANTOS, Marilin Mariano; MATAl, Patrícia Helena Lara dos Santos. A importância da industrialização do xisto brasileiro frente ao cenário energético mundial. Revista Escola de Minas. Ouro Preto, 63(4): 673-678, out. dez. 2010.

HAUSMAN, Catherine; KELLOGG, Ryan. Welfare and Distributional Implications of Shale Gas. In: Brookings Papers on Economic Activity. p. 1-45. Base de dados: Business Source Elite, 2015.

MARINHO, Frederico Augusto. A eficiência energética e a gestão pública integrada - desafios e propostas energéticas. In: OLIVEIRA, Fátima Bayma de (Org.). Política de gestão pública integrada. Rio de Janeiro: Editora FGV, 2008.

LEITE, Antônio Dias. A economia brasileira: de onde viemos e onde estamos. 2. ed. Rio de Janeiro: Elsevier, 2011.

LEITE, José Rubens Morato; AYALA, Patrick de Araújo. A transdisciplinariedade do direito ambiental e a sua equidade intergeracional. In: MILARÉ, Édis; MACHADO, Paulo Affonso Leme (Org.). Doutrinas essenciais de direito ambiental. Vol. I (mar. 2011). p. 977-999. São Paulo: Revista dos Tribunais, 2011. PEIXOTO, Gabriela Costa Cruz Cunha. Análise econômica do direito ambiental: aplicação das teorias de Pigou e Coase. Revista Direito e Liberdade, Natal, v. 15, n. 3, p. 31-48, set./dez. 2013. Quadrimestral. Disponível em: http://www.esmarn.tjrn.jus.br/revistas/index.php/revista _direito_e_liberdade/article/viewFile/551/523. Acesso em: 27 de setembro de 2016.

SACHS, Ignacy. Primeiras intervenções. In: NASCIMENTO, Elimar Pinheiro do; VIANNA, João Nildo (Orgs.). Dilemas e desafios do desenvolvimento sustentável no Brasil. Rio de Janeiro: Garamond, 2007. SANTOS, Thiago Flores dos; FREITAS, Ana Carla Pinheiro. Logística reversa como função essencial à efetivação da responsabilidade ambiental empresarial. In: MAIA, Fernando Joaquim Ferreira; ARAÚJO, Jailton Macena de; BORGES, Maria Creusa (Org.). Prima Facie: Direito, História e Política [Recurso eletrônico] / Universidade Federal da Paraíba, Centro de Ciências Jurídicas, Programa de Pós-Graduação em Ciências Jurídicas. João Pessoa: PPGCJ, v. 16, n. 32, mai./ago. 2017. p. 1-35. Online.

SILVA, José Afonso da. Direito ambiental constitucional. 10aed. São Paulo: Malheiros Editores, 2013. TRENNEPOHL, Curt; TRENNEPOHL, Terence. Licenciamento ambiental. 6 ed. ver. e atual. São Paulo: Editora Revista dos Tribunais , 2016

Trabalho recebido em 04 de outubro de 2018

Aceito em 20 de fevereiro de 2019

Revista de Direito da Cidade, vol. 11, no 3. ISSN 2317-7721. pp. 14-38 